\title{
Randomized controlled trial of a positive affect intervention to reduce stress in people newly diagnosed with HIV; protocol and design for the IRISS study
}

\author{
This article was published in the following Dove Press journal: \\ Open Access Journal of Clinical Trials \\ 22 September 2014 \\ Number of times this article has been viewed
}

\begin{abstract}
Judith Tedlie Moskowitz
Adam W Carrico ${ }^{2}$

Michael A Cohn ${ }^{3}$

Larissa G Duncan ${ }^{4}$

Cori Bussolari ${ }^{5}$

Kristin Layous ${ }^{6}$

Jen R Hult ${ }^{7}$

Alex Brousset ${ }^{8}$

Paul Cotten ${ }^{3}$

Stephanie Maurer ${ }^{3}$

Martha E Pietrucha ${ }^{3}$

Michael Acree ${ }^{3}$

Judith Wrubel ${ }^{3}$

Mallory O Johnson 9,10

Frederick $\mathrm{M} \mathrm{Hecht}^{3}$

Susan Folkman 9,10
\end{abstract}

'Department of Medical Social Sciences, Feinberg School of Medicine, Northwestern University, Evanston, IL, ${ }^{2}$ Community Health Systems.

School of Nursing, University of California San Francisco, San Francisco, CA, ${ }^{3}$ Osher Center for Integrative Medicine, University of California San Francisco, San Francisco, CA, ${ }^{4}$ Department of Family and Community Medicine, Osher Center for Integrative Medicine, University of California San Francisco, San Francisco, CA, ${ }^{5}$ Department of Counseling Psychology, School of Education, University of San Francisco, San Francisco,

CA, ${ }^{6}$ Department of Psychology, University of California Riverside, Riverside, CA, Institute for Health Policy Studies, University of California San Francisco, San Francisco, CA, ${ }^{8}$ Center for HIV Education Studies and Training, City University of New York, New York, NY, 'Osher Center for Integrative Medicine, University of California San Francisco, San Francisco, CA, ${ }^{\circ}$ Department of Medicine, University of California San Francisco, San Francisco, CA, USA

Correspondence: Judith T Moskowitz Department of Medical Social Sciences, 633 N. St. Clair, Suite 1900, Chicago, IL 606II, USA Email judith.moskowitz@northwestern. edu

\begin{abstract}
Increasing evidence suggests that positive affect plays an important role in adaptation to chronic illness, independent of levels of negative affects like depression. Positive affect may be especially beneficial for people in the midst of severe stress, such as the diagnosis of human immunodeficiency virus (HIV). As medical treatments for HIV have improved, the number of people living with HIV has increased, and prevention strategies tailored specifically to people living with HIV have become a priority. There is a need for effective, creative, client-centered interventions that can be easily disseminated to community treatment settings, but there are currently few established interventions for people who are newly diagnosed with HIV. We present the design and methods for a randomized trial in which we test the efficacy of one such skills-based intervention that targets positive affect as a novel mechanism of change. The proposed research builds on observational findings of the important unique functions of positive affect. We aim to determine whether a five-session theoryand evidence-based intervention designed to teach skills for increasing the frequency and intensity of daily positive affect does so, and whether this intervention has beneficial effects on subsequent psychological well-being, health behaviors, and physical health up to 15 months after diagnosis with HIV. This is a randomized controlled trial in a sample of adults recruited within 12 weeks of testing positive for HIV. The control group is attention-matched, and follow up assessments will be conducted immediately post intervention (approximately 5 months post diagnosis) and at 10 and 15 months post diagnosis. This study is an important next step in research concerning the adaptive functions of positive affect for people coping with HIV or other health-related life stress.
\end{abstract}

Keywords: positive affect, HIV diagnosis, stress, coping, RCT, intervention, physical health

\section{Introduction}

Depression is common in people living with human immunodeficiency virus ${ }^{1}$ (HIV) and is associated with substance abuse, ${ }^{2-4}$ suboptimal medication adherence, ${ }^{5-7}$ increased HIV transmission risk behavior, ${ }^{3}$ and hastened HIV disease progression. ${ }^{8-10}$ Depression, however, is only part of the emotion picture. Increasing evidence suggests that positive affect plays an important role in adaptation to chronic illness, independent of levels of negative affects like depression. ${ }^{11,12}$ Positive affect may be especially beneficial for people in the midst of severe stress, such as the diagnosis of HIV. ${ }^{13-16}$ A growing body of research shows that positive affect has unique beneficial associations with psychological and physical health in the context of health-related stress. ${ }^{13,17-21}$

In the era of HIV treatment as prevention (TaSP), initiating anti-retroviral therapy (ART) immediately following HIV diagnosis has the potential to optimize health outcomes and reduce transmission rates by promoting sustained HIV viral suppression. ${ }^{22}$ 
However, newly diagnosed HIV-positive persons experience substantial barriers such as depression and substance use that hinder linkage to and engagement in HIV medical care. ${ }^{23}$ Interventions for people with HIV targeting depression, stress, and associated HIV risk behaviors have shown modest effects, ${ }^{24-28}$ but there remains a clear need for improvement. ${ }^{29}$ The prevalence of comorbid depression in HIV remains elevated, ${ }^{30} \mathrm{HIV}$ incidence has not dropped appreciably, ${ }^{31}$ and a significant proportion of people living with HIV continue to engage in behaviors that put them at risk for other sexually transmitted diseases and their partners at risk of infection with HIV. ${ }^{32}$

There is a need for effective, creative, client-centered interventions to realize the potential benefits of TasP and to facilitate optimal adjustment to HIV. We present the clinical trial design and rationale for a skills-based intervention for people newly diagnosed with HIV that targets positive affect as a fundamental and novel mechanism of change, and promotes resilience in the midst of serious life stress. This randomized controlled trial (RCT) tests whether a five-session theory- and evidence-based intervention designed to teach skills for increasing the frequency and intensity of daily positive affect does so, and whether these intervention-related increases in positive affect have beneficial effects on subsequent psychological well-being, health behaviors, and physical health up to 15 months after diagnosis with HIV.

\section{The stress of being diagnosed with HIV}

People newly diagnosed with HIV are in the acute phase of a major stressful life event and face significant challenges including the need to interact with a complex health care system; constraints on sexual behavior; decision-making around disclosure of serostatus to friends, family, and sexual partners; stigma; and in many cases a struggle to come to terms with a new identity as someone living with HIV. ${ }^{33,34}$

The period immediately following human immunodeficiency virus positive (HIV+) serostatus notification is characterized by increases in depression and anxiety. ${ }^{35-41}$ Even years after diagnosis, people living with HIV are at elevated risk of depression, ${ }^{1}$ which is associated with a number of negative outcomes including increased sexual risk behavior ${ }^{3}$ and more rapid HIV disease progression. ${ }^{8-10}$ Although interventions designed to reduce depression in people living with HIV have met with some moderate success, ${ }^{24,28,42}$ very few have targeted those who are newly diagnosed with HIV.

\section{Stress and the relevance of positive affect}

The intervention we present here focuses on positive affect. Both theory and research support this approach. We use the term "affect" broadly, to include any positively or negatively valenced subjective feeling state. Examples of positive affects are: happiness, contentment, joy, satisfaction, gratitude, relief, and pleasure. These are differentiated from negative affects such as sadness, anger, fear, disgust, shame, and distress. We are interested in the impact of the intervention on the frequency and intensity of positive affects and their impact on subsequent health behaviors and well-being.

\section{Positive affect co-occurs with negative affect during stressful periods}

Positive affect can occur with relatively high frequency, even in the midst of dire stressful circumstances, and can occur at the same time that symptoms of depression and distress are significantly elevated. In our study of caregiver partners of men with Acquired Immune Deficiency Syndrome (AIDS), the depression scores of the caregivers in the study were in the range that would classify them as at risk for clinical depression, both during caregiving and after the death of the partner. ${ }^{43}$ However, with the exception of the time immediately surrounding the death of the partner, when asked to report how often they experienced various positive and negative affects in the previous week, the participants reported experiencing overall positive affect as least as frequently as they experienced overall negative affect. ${ }^{13}$ Three years after the death of the partner, the mean depression score of the bereaved caregivers was still significantly higher than the general population mean. ${ }^{44}$ Again, however, positive affect was prevalent.

\section{Adaptational significance of positive affect during stressful periods}

The fact that positive affect co-occurs with negative affect suggests that positive affect is adaptive in the context of stress. ${ }^{13-16,45-47}$ Several empirical studies support this hypothesis. For example, in a 12 -week study of women with arthritis or fibromyalgia, positive affect was associated with reduced pain and lowered negative affect, and this relationship was stronger during weeks when participants reported higher levels of stress. ${ }^{48}$ Similarly, in a longitudinal study of widows, daily positive affect buffered the effect of stress on negative affect. Compared to periods of low stress, positive affect in periods of high stress predicted lower levels of negative affect. ${ }^{49}$ 
Laboratory and epidemiological studies suggest positive affect may also affect physiological outcomes, morbidity, and mortality. For example, laboratory studies suggest that positive affect may have beneficial physiological effects in the context of stress. Fredrickson and Levenson ${ }^{50}$ induced negative affect in subjects by showing them a film that elicited fear. Subjects were then shown one of four films designed to elicit contentment or amusement (positive affect), sadness (negative affect), or no affect (neutral condition). Measures of cardiovascular reactivity indicated that those individuals who were shown the contentment or amusement film had faster recovery to baseline than subjects shown the sad or neutral film.

With respect to morbidity and mortality, studies have indicated that positive affect is uniquely associated with lower risk of morbidity and mortality across both chronically ill and healthy samples. ${ }^{12,51}$ Mroczek et $\mathrm{al}^{52}$ demonstrated that although levels of positive and negative affect over the course of an 8-day diary study were not predictive of 10 -year mortality risk, positive affect reactivity (the extent to which positive affect dropped in response to a stressful event) was. Participants who maintained their normal level of positive affect during days in which they experienced a stressor had lower mortality than those whose positive affect dropped.

In a sample of men with AIDS, participants with higher average scores on the positive affect subscale from the Center for Epidemiological Studies Depression scale (CES-D) had lower risk $(\mathrm{RR})$ of mortality compared to those with lower positive affect: $\mathrm{RR}=0.89,95 \% \mathrm{CI}-0.84-0.95 .{ }^{20}$ When risk estimates were adjusted for the time-dependent covariates of CD4, antiretroviral use, and the other subscales of the CES-D, positive affect remained significantly predictive of lower risk of AIDS mortality $(\mathrm{RR}=0.90, \mathrm{CI}=0.85-0.97$ ). These provocative, observational studies suggest that positive affect may counteract some of the negative physiological and psychological effects associated with stress and, ultimately, lead to better health outcomes.

\section{Mechanisms through which positive affect might influence clinical outcomes}

One pathway through which positive affect may buffer adverse effects of stress is by increasing coping resources, such as social support, that enable the individual to cope better with the stress of HIV in a variety of ways. ${ }^{53}$ Positive affect is hypothesized to facilitate social support, and social support has been shown to be associated with longer survival and slower progression of HIV ${ }^{54,55}$ In HIV-negative samples, positive affect is associated with greater social connectedness, when controlling for negative affect and other potential confounders. ${ }^{56}$ In another study, Keltner and Bonanno ${ }^{57}$ found that bereaved individuals who showed genuine laughs or smiles (as determined by coding of facial expressions), while describing their relationship with their deceased spouse, elicited more positive affect and less frustration in observers than bereaved individuals who did not show the genuine laughs or smiles. Perhaps more importantly, untrained observers indicated that they would be more likely to offer comfort to those individuals who showed the genuine laughs or smiles. These findings suggest that individuals may elicit social support from others by their displays of positive affect.

Positive affect may influence risk of mortality by bolstering the immune system directly. Various immune parameters have been shown to be susceptible to influence by experimentally induced, as well as naturally occurring, affective states. ${ }^{58,59}$ These findings may not fully generalize to individuals with HIV, but HIV-specific studies suggest that similar processes occur. Ickovics et $\mathrm{al}^{60}$ found that psychological resources (an index that combined positive affect, positive health expectancies, and finding meaning) were associated with lower risk of mortality and slower CD4 decline, suggesting a possible immune mediator of the link between positive psychological states and physical health in people with HIV. Work by Antoni et al demonstrates that stress management interventions designed to reduce distress in HIV+ samples improve immune function (eg, increased CD4/CD8 ratio, increased natural killer [NK] cytotoxicity). ${ }^{54,61-64}$ Although stress management interventions both increase positive affect and decrease negative affect, positive affect has not been explicitly assessed as a mediator of the association of stress reduction interventions and improvement in immune parameters.

Positive affect may also lower risk of morbidity and mortality via improved health behaviors. A study of daily affect and sexual risk behavior in men who have sex with men (MSM) demonstrated a unique effect of positive affect: participants who reported higher positive affect were less likely to engage in risky sexual behavior, controlling for negative affect and sexual feelings. ${ }^{65}$ Positive affect is associated with subsequent reductions in stimulant use among $\mathrm{MSM},{ }^{66}$ and recent work demonstrates that positive affect predicts subsequent engagement in health care among people newly diagnosed with HIV. ${ }^{17}$ Positive affect may facilitate attention to and 
processing of health-relevant information, which is a crucial step in health-promoting behaviors. ${ }^{67,68}$ These findings extend evidence on the effects of positive affect into the realm of health behavior, suggest the possibility that increases in positive affect may help HIV+ individuals attend to information regarding their health, and perhaps facilitate more effective health care utilization. We hypothesize that a positive affect intervention will increase positive affect which will, in turn, be associated with improved health behaviors (Figure 1).

\section{Theoretical foundation of the intervention}

The intervention is based on revised stress and coping theory ${ }^{13,69}$ and the broaden-and-build theory of positive emotion. ${ }^{53}$ Folkman ${ }^{13}$ proposed a revision to stress and coping theory that explicitly posits a role for positive affect in the coping process. According to the original theory, ${ }^{70}$ the coping process begins when an event is appraised as threatening, harmful, or challenging. These appraisals are associated with affect (negative affect in response to threat or harm, a mix of positive and negative in response to challenge), and prompt coping. If the event is resolved favorably, a positive affective state is the result. If the event is resolved unfavorably or if it is unresolved, a negative affective state results and the coping process continues through reappraisal and another round of coping. The revised model suggests that the negative affect associated with unfavorable resolution motivates coping processes that draw on important goals and values, including positive reappraisal and goal-directed problem-focused coping. These coping processes result in positive affect, which serves important coping functions: positive affect provides a psychological "time-out" from the distress associated with chronic stress, and it helps motivate and sustain ongoing efforts to cope with the negative effects of the chronic stress. In the context of a new HIV diagnosis,

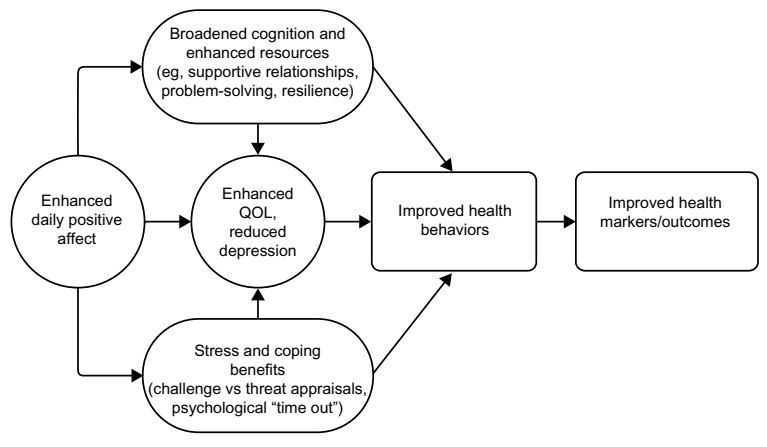

Figure I Theoretical model of pathways through which positive affect is associated with health.

Abbreviation: QOL, quality of life. positive affect may facilitate more adaptive coping such as positive reappraisals where individuals change their thoughts about stressful circumstances to see them in a more positive light (eg, "this has made me a stronger person.") It may also be that positive affect leads to decreased reliance on avoidantoriented coping strategies (eg, stimulant and other drug use, and unsafe sexual behavior).

Fredrickson ${ }^{53}$ proposed the "broaden-and-build" model of the function of positive affect that complements revised stress and coping theory. In this model the "broadening" function of positive affect enables the individual to see beyond the immediate stressor and possibly come up with creative alternative solutions to problems. The "building" function helps to rebuild resources (such as self-esteem and social support) depleted by enduring stressful conditions. In contrast to the narrowing of attention and specific action tendencies associated with negative affect, positive affect broadens the individual's attentional focus ${ }^{71-73}$ and behavioral repertoire. ${ }^{71,74}$ Repeated experiences of positive affect build social, intellectual and physical resources that buffer against the deleterious effects of stress. ${ }^{45,75-77}$ Although the broaden-and-build model is not specific to stress, under stressful conditions the functions of positive affect suggested by the model become especially important. In the context of a new HIV diagnosis, positive affect may support adjustment to living with this chronic illness, and enhance receptivity to health promotion messages (the broadening function) in the critical period when newly diagnosed individuals are establishing new self-care behaviors, including engagement in health care and safer sexual behaviors.

\section{Design and methods}

The study, called IRISS (Intervention for those Recently Informed of their Seropositive Status), is a five-session positive affect skills intervention compared to an attention-matched control condition, in which participants have five sessions of interviews concerning coping and affect. Both intervention and control sessions are approximately one hour long and are administered one-on-one by trained facilitators. Participants in both conditions have daily home practice over the 5 weeks of the intervention. At the end of the 15-month assessment period, participants in the control condition are offered the opportunity to learn the skills in a self-paced online format.

\section{Participants Eligibility}

To be enrolled in this RCT, participants must: 1) have been informed they were HIV positive within the past 12 weeks; 
2) speak English or Spanish; 3) be 18 years or older; and 4) have the ability to provide informed consent to be a research participant. Exclusion criteria include: 1) Inability to provide informed consent, as evidenced by cognitive impairment; 2) active psychosis; and 3) unmedicated bipolar disorder. All procedures were approved by the relevant Human Subjects Committees, and all participants provided written informed consent.

\section{Study procedures Recruitment}

Participants were recruited through HIV testing sites and clinics, community based organizations, newsletters, and fliers. Potential participants were informed that the goal of the study was to find out what's effective in helping people cope with a new diagnosis. Study materials and consent forms explained that participants would be assigned to one of two conditions in which they would either "learn skills to better manage your mood" or "talk about what's going on since testing positive." They were also told they would have three blood draws to measure CD4 and viral load, and would receive up to $\$ 250$ for completing nine visits over 15 months. Interested participants were referred to the study for screening. Participants who were eligible were then scheduled for their first assessment session.

\section{Consent, assessments, and randomization}

Scheduled assessments take place at four points: Time 1 (baseline) at entry into the study within approximately 3 months post diagnosis; Time 2, at one week postintervention (approximately 5 months post diagnosis); Time 3 (approximately 10 months post diagnosis);

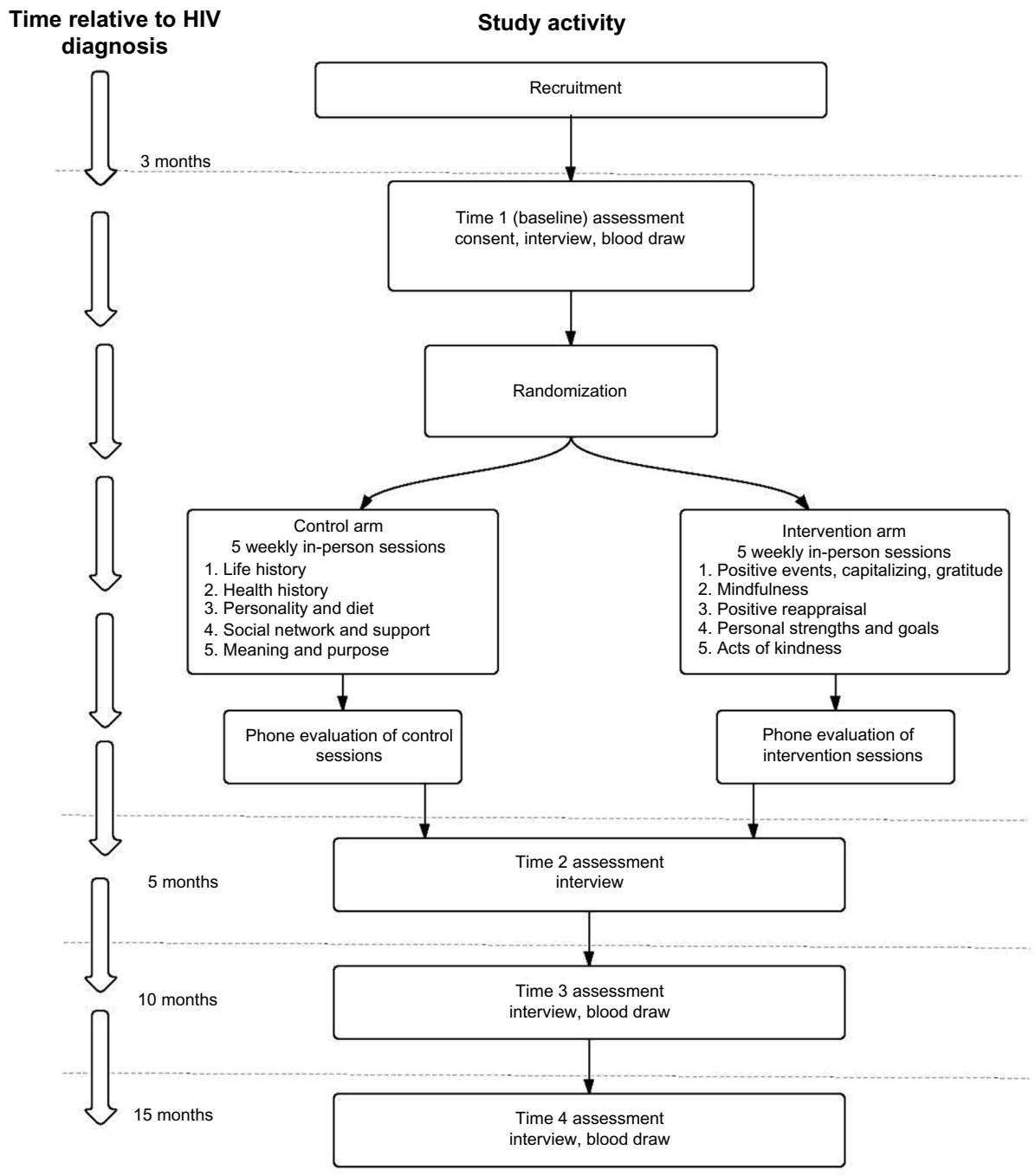

Figure 2 Study recruitment and assessment timeline. Abbreviation: HIV, human immunodeficiency virus. 
and Time 4 (approximately 15 months post diagnosis.) CD4 and viral load are collected at Time 1, Time 3, and Time 4 (15 months post diagnosis). See Figure 2.

Assessments are conducted one-on-one by trained interviewers who are blind to whether the participant was in the intervention or the control condition. Assessments consist of quantitative self-reports on positive and negative affect, health behaviors, physical health, coping, social support, and personality; measures are shown in Table 1. Qualitative data are collected on recent HIV-related stressful events. We use computer assisted personal interviewing and all interviews are audio recorded for quality control and later transcription and analysis of the narrative portions. Participants are video recorded during their stressful event narrative at Times 1, 2, and 4 for coding of facial expressions of emotion. All study materials have been translated into Spanish by a certified translator.

At the first assessment session, participants complete informed consent procedures, have an initial blood draw for CD4 and viral load, and complete the baseline interview. Once the baseline assessment is completed, the participant is randomly assigned to the intervention or control condition using block randomization with randomly-varying block sizes of two, four, or six.

\section{Content of the intervention}

Elsewhere, we have detailed the rationale for inclusion of each of the positive affect skills. ${ }^{78}$ Briefly, the IRISS intervention consists of five in-person sessions and one phone session in which facilitators teach participants eight empirically-supported behavioral and cognitive "skills" for increasing positive affect. The eight skills are: 1) noting daily positive events; ${ }^{79-82}$ 2) capitalizing on or savoring positive events, ${ }^{83,84}$ 3) gratitude; ${ }^{85-87}$ 4) mindfulness, ${ }^{88-91}$ 5) positive reappraisal; ${ }^{13,24,42,92-96} 6$ ) focusing on personal strengths, ${ }^{97-99}$ 7) setting and working toward attainable goals; ${ }^{42,95,100-103}$ and 8) small acts of kindness. ${ }^{104-108}$

The first session begins with an overview of the intervention approach and philosophy. We explicitly acknowledge to the participant that testing positive for HIV is very stressful for most people and that we are not advocating a simplistic “don't worry - be happy” approach. We explain to participants that although this is a structured, positive affect skills-building intervention, they should feel free to discuss their HIV status or other stressors in the sessions if and when it feels comfortable to them. We also do not require participants to discuss these issues. We emphasize that our goal is to help participants give time and attention to the positive experiences and associated emotions, even in the context of serious life stress.

\section{Session I}

In the first session, we focus on positive events, capitalizing, and gratitude. The facilitator explains that even under extremely stressful conditions, people have the capacity to experience positive events. The purpose of this part of the session is to help participants recognize positive events and the associated positive affect associated with those events. During this part of the session, the facilitator helps participants understand that when they experience a positive event, they may capitalize on it by "turning up the volume" (ie, increasing the intensity) of the associated positive affect by telling someone about it, writing about it, or simply reflecting on the event and re-experiencing it. ${ }^{83}$ The home practice after Session 1 consists of the participant noting a positive event each day and writing about it (capitalizing), and starting a daily gratitude journal in which the participant lists at least one thing to be grateful for that day. The gratitude list continues through the rest of the 5-week intervention period. Participants are encouraged to list small things (eg, a good cup of coffee, a smile from a stranger) as well as bigger things. Finally, participants are asked to complete a daily brief measure of positive and negative affect on their own (control group participants also complete this measure).

\section{Session 2}

The focus in Session 2 is mindfulness, a state in which one focuses on the present moment, accepting and acknowledging it without getting caught up in emotional reactions or ruminative thoughts about the situation. During this session, the facilitator discusses the concept of developing mindfulness through formal practice, and then practices a formal mindfulness activity with the participant, eg, sitting quietly and paying attention to the breath, guided by a 10-minute "breath awareness" audio recording. The audio instructions and the discussion following the breath awareness activity emphasize nonjudgment of thoughts and feelings that arise during the activity. We give participants a copy of the audio recording to use for their home practice (and loan them an audio listening device if they do not have one readily available for their use). This is followed by discussion and practice of informal mindfulness (mindfulness of daily activities such as a phone conversation, walking or driving, or doing a household chore). Home practice for the week following Session 2 consists of daily informal mindfulness activities, the 10-minute formal breath awareness activity, and continuing the gratitude journal and daily emotion reports that were started in the first week. Participants are instructed to continue the daily breath awareness activity throughout the remaining weeks of the intervention. 
Table I Outcome, moderator, and intervention-based measures

Measure Description

\section{Outcomes (Times I through 4 unless otherwise noted)}

Affect

Modified Differential Emotions Scale (mDES) ${ }^{45}$

Positive and Negative Affect Schedule (PANAS) ${ }^{117}$

Daily affect diary

\section{Mental health PRIME-MD ${ }^{\prime \prime}$}

The Center for Epidemiological Studies Depression (CES-D) Scale ${ }^{119}$

Spielberger State-Trait Anxiety Inventory (STAI) ${ }^{120}$

Perceived Stress Scale ${ }^{|2|}$

\section{Physical health}

Physical symptoms ${ }^{122}$

CD4 and viral load

\section{Health behaviors}

Sexual risk behaviors ${ }^{123}$

Alcohol/drug use

Medication adherence ${ }^{124,125}$
This version of the DES includes a wider range of positive emotions than the original scale. The full scale assesses interest, enjoyment, surprise, sadness, anger, disgust, contempt, fear, guilt, shame, shyness, amusement, awe, contentment, gratitude, hope, love, pride, sympathy, and sexual feelings. Participants rate how frequently they felt that particular affect in the past week on a five-point scale: $0=$ never, $\mathrm{I}=$ hardly, $2=$ some of the time, $3=$ often, and $4=$ most of the time.

The PANAS was designed to assess two relatively independent constructs: high activation positive affect (eg, interested, excited, enthusiastic) and high activation negative affect (upset, irritable, ashamed). Respondents are asked to indicate how strongly they felt each affect during the past week on a scale from $0=$ not at all to $4=$ extremely.

Over the 5 weeks of the intervention, both intervention and control group participants report their affect at the end of each day in a diary format. For this purpose we reworded the mDES described above to indicate a time frame of "today" instead of "past week."

The Prime MD assesses clinical depression with ten questions regarding depressive symptoms (eg, trouble falling asleep or staying asleep, poor appetite or overeating, little interest or pleasure in doing things). A respondent is considered clinically depressed if he/she responds affirmatively to five of nine symptoms in which one of the symptoms is depressed mood and/or anhedonia (not wanting to do anything). The CES-D was used to measure depressive mood during the past week. The CES-D consists of 20 items which are rated on a four-point scale according to how frequently they were experienced in the previous week: $I=$ rarely or none of the time (less than one day), $2=$ some or a little of the time (I-2 days), $3=$ occasionally or a moderate amount of time (3-4 days), or 4= most or all of the time (5-7 days). The STAI assesses feelings of tension, nervousness, and worry. The first 20 items measure state anxiety (how one feels at the moment) and the last 20 items measure trait anxiety (how one generally feels). Participants rate the frequency with which they feel or think in ways that indicate presence or absence of anxiety, eg, "I feel nervous and restless", or "I feel pleasant" on a four-point scale (almost never, sometimes, often, almost always).

This four-item version of the scale measures perceived stress with items such as "How often have you felt difficulties were piling up so high that you could not overcome them?" Participants rate the frequency of the feeling on a five-point scale $(0=$ never, through $4=$ very often $)$.

Physical symptoms are assessed using a modification of the scale developed by the AIDS Clinical Trials Group. Participants are asked whether they have experienced each of a series of 38 possible symptoms in the preceding 30 days and how much the problem bothered them.

Trained phlebotomists obtain approximately $15 \mathrm{~mL}$ of blood for CD4 cell count and plasma HIV RNA viral load using the bDNA assay (Bayer, Emeryville, CA, USA). Assays are run by Quest Diagnostics, Madison, NJ, USA.

The sexual behavior questionnaire asks the number of male and female sexual partners in the past 3 months, and whether the participant engaged in receptive anal sex with or without a condom, vaginal sex with or without a condom, receptive oral sex with or without a condom, and oral sex with or without a barrier. In addition, for each of the behaviors, the participant is asked how many of the partners he/she knew were $\mathrm{HIV}+$.

Alcohol use is assessed by asking how much beer, wine, and liquor the participant consumed in a typical week during the past month. Drug use is assessed by asking which drugs were used in the past month to get high and how often in the past month they were used. Response options include cocaine, crack, amphetamines, downers, marijuana, ecstasy, poppers, and other. Injection drugs are assessed separately and options include heroin, cocaine, crack, speed, and other. Participants are also asked whether they shared needles or cookers during the last 3 months, how many people they shared with in the past 3 months, and how many times needles that were not cleaned were shared in the past 3 months. Finally, participants are asked how many HIV+ people they shared needles or cookers with in the last 3 months. Participant adherence to antiretroviral therapy over the past 30 days is assessed using a visual analog scale. For each HIV medication prescribed, the participant is asked to indicate how much of each drug they have taken in the past 30 days by placing a line on a $10 \mathrm{~cm}$ scale marked from $0 \%$ to $100 \%$. From this data, adherence can be calculated as an average across all medications. In addition, we ask how many doses were missed in the last 7 days. 
Table I (Continued)

\begin{tabular}{|c|c|}
\hline Measure & Description \\
\hline Health attitudes and behaviors & This 27-item scale measures two underlying health behavior dimensions: preventative behaviors (eg, exercise) \\
\hline \multirow[t]{6}{*}{ checklist $^{126}$} & and risk-taking behaviors (eg, drinking). Responses are made on a five-point scale based on participants' \\
\hline & engagement in that health behavior in the past week. At Times 2,3 , and 4 , we also assessed the extent to \\
\hline & which participants were engaging in each of the eight skills taught in the intervention. For example, items such \\
\hline & as "In the past week, how often did you set a goal and work toward it?" (goal setting) or "How often did you \\
\hline & do something nice for someone else?" (acts of kindness) will be embedded with items from the checklist such \\
\hline & as "How often did you exercise?" and "How often did you wear a seatbelt?" \\
\hline
\end{tabular}

Ways of Coping Scale ${ }^{\mid 27-131}$

\section{Coping resources}

Multidimensional Social

Support Inventory ${ }^{132}$

Moderators (assessed at Time I only)

NEO Five-Factor Inventory $(\mathrm{NEO}-\mathrm{FFI})^{133}$

Life Orientation Test-Revised $\left(\right.$ LOT-R) ${ }^{134}$

Rosenberg Self-Esteem Scale (RSE) ${ }^{135}$

World Assumptions Scale (WAS) ${ }^{136}$

Subjective socioeconomic status $^{137}$

Hassles and Uplifts Scale ${ }^{138}$
Participants are asked to complete the coping items with reference to testing positive for HIV (at Time I) or the most stressful situation associated with having HIV that occurred during the previous week (at Times 2, 3, and 4). The coping scale consists of a range of cognitive and behavioral strategies to cope with the stressful encounter, eg, "Talked to someone who could do something about the problem," or "Went on as if nothing had happened" on a four-point scale $(0=$ does not apply and/or not used; through $3=$ used a great deal). The participant also responds on other scales hypothesized to be correlated with positive affect. The 23 assessed forms of coping responses include: confrontive coping, escape-avoidance, planful problem-solving, positive reappraisal, benefit, growth, mastery of stress, other success, purpose, positive relations with others, religion and respite, benevolent and negative religious coping, emotional processing and expression, goal replacement, and maintaining optimism.

This scale assesses practical, emotional, affirmational, HIV, negative, and general support. For each dimension of support, the respondent is asked whether there is someone to provide that type of support (yes/no); if yes, who that person is, and their relationship to the respondent. In addition to perceived availability of each type of support, respondents are asked how often they needed each type of support in the past month, and how often they actually received it. We will compute separate practical, emotional, affiliative, HIV, negative, and general support scales.

The NEO-FFI is a 60-item scale that measures 12 aspects of each of five factors of personality (Neuroticism, Extraversion, Openness, Agreeableness, and Conscientiousness). Neuroticism has been shown to be associated with negative affect, and extraversion with positive affect, by Rusting and Larsen ${ }^{143}$ The NEO-FFI has shown excellent reliability and validity in a wide variety of samples and has reasonable associations with coping (Costa et al $^{144}$ ).

Optimism, or generalized positive expectancies, will be assessed with the ten-item revised version of the Life Orientation Test-Revised. The LOT-R asks participants to rate their level of agreement with items such as "in uncertain times, I usually expect the best" on a six-point scale $(0=$ strongly disagree, though $5=$ strongly agree). The LOT-R has good reliability, as well as excellent predictive and discriminant validity. Self-esteem was assessed with the RSE, a ten-item measure that asks participants to rate their level of agreement to items such as "On the whole, I am satisfied with myself" on a five-point scale ( $I=$ strongly disagree, through $5=$ strongly agree). The RSE is the most widely used measure of self-esteem and has been shown to be reliable and valid in a wide variety of samples, including crack users (Falck et $\mathrm{al}^{145}$ ) and Spanish-speaking samples (Baños and Guillén ${ }^{146}$ ).

The 32-item WAS assesses people's worldviews by asking them to rate their level of agreement with items such as "Most people can be trusted" and "Anyone can experience a very bad event" on a sevenpoint scale ( $I=$ strongly agree, through $6=$ strongly disagree). The WAS assesses three main categories of assumptions: benevolence of the world, eg, "There is more good than evil in the world", meaningfulness of the world, eg, "Through our actions, we can prevent bad things from happening to us", and self-worth, eg, "I am very satisfied with the kind of person I am." The subscales demonstrate good reliability across samples (between $\alpha=0.8 \mathrm{I}$ and 0.87 ).

To assess subjective socioeconomic status, participants are presented with a drawing of a ladder with ten rungs that is described as follows "Think of this ladder as representing where people stand in our society. At the top of the ladder are the people who are the best off, those who have the most money, most education, and best jobs. At the bottom are the people who are the worst off, those who have the least money, least education, and worst jobs or no job." They are then asked to place an X on the rung that best represents where they think they stand on the ladder.

Hassles/uplifts are assessed with a shortened (57-item) version of the Hassles and Uplifts scale. Hassles are defined as "irritants - things that annoy or bother you" and uplifts are "events that make you feel good." For each event on the Hassles/Uplifts scale, the participant indicates whether it has been a hassle or an uplift since the last interview. The scale is scored by calculating separate hassle and uplift scores. 
Table I (Continued)

\begin{tabular}{|c|c|}
\hline Measure & Description \\
\hline Life Experiences Survey ${ }^{139}$ & $\begin{array}{l}\text { Major life events are assessed with a modified version of the Life Experiences Survey. We assess whether } \\
\text { any of the } 49 \text { items on the scale occurred since the last assessment. For those that did occur, participants } \\
\text { are asked to rate whether the event had a positive or negative impact. }\end{array}$ \\
\hline \multicolumn{2}{|l|}{ Intervention-based mediators } \\
\hline $\begin{array}{l}\text { Gratitude Questionnaire-6 } \\
(\text { GQ-6) }\end{array}$ & $\begin{array}{l}\text { Gratitude is measured with the GQ-6, a six-item scale that asks participants to rate their level of } \\
\text { agreement with statements such as "I have so much in life to be thankful for" on a eight-point scale } \\
\text { where I= strongly disagree and } 7=\text { strongly agree. We modified the wording of specific items to capture } \\
\text { experiences of gratitude in the past month. }\end{array}$ \\
\hline Five-Factor Mindfulness Scale ${ }^{14 \mid}$ & $\begin{array}{l}\text { We assessed mindfulness using a revised version of the Five-Factor Mindfulness Scale used in our pilot } \\
\text { work. The scale was shortened to contain } 19 \text { Likert-type items, and slight changes were made to the } \\
\text { wording of several items to ensure that they were appropriate for use with participants who had no } \\
\text { prior meditation experience. Respondents are asked to indicate how frequently they experience several } \\
\text { facets of mindfulness, including present-centered awareness and attention (eg, "You find it difficult to stay } \\
\text { focused on what's happening in the present." - reverse scored); non-judgment (eg, "You criticize yourself } \\
\text { for having irrational or inappropriate emotions." - reverse scored); and non-reactivity (eg, "When you } \\
\text { have distressing thoughts or feelings, you just notice them and let them go"). Response options range } \\
\text { from I= never to } 5=\text { always. }\end{array}$ \\
\hline Coping Self-Efficacy Scale ${ }^{142}$ & $\begin{array}{l}\text { Personal strengths in the context of stress were assessed using the I3-item coping self-efficacy scale } \\
\text { which measures self-efficacy in three main areas: using problem-focused coping (eg, "Break an upsetting } \\
\text { problem up into smaller parts"), stopping unpleasant emotions and thoughts (eg, "Make unpleasant } \\
\text { thoughts go away"), and getting support from family and friends ("Get friends to help you with the things } \\
\text { you need"). Participants were asked to rate the degree to which they could perform the listed behaviors } \\
\text { on an eleven-point scale: } 0=\text { cannot do at all, } 5=\text { moderately certain can do, and } 10=\text { certain can do. We } \\
\text { added items to assess self-efficacy in increasing positive affect. }\end{array}$ \\
\hline
\end{tabular}

Abbreviations: AIDS, acquired immune deficiency syndrome; HIV, human immunodeficiency virus; HIV+, human immunodeficiency virus positive; RNA, ribonucleic acid; bDNA, branched deoxyribonucleic acid.

\section{Session 3}

In Session 3, we focus on the coping skill of positive reappraisal. The participant is introduced to the concept of appraisal, a person's interpretation or judgment about the personal significance of an event. The facilitator explains that because our appraisals determine our emotional reaction to an event, if we can change our appraisals, we can change how we feel. Positive reappraisal is a way of dealing with stress in which the individual makes a positive change in how an event is interpreted or appraised. Noting that the event may not be as bad as originally thought, was not as bad as it could have been, or noting something positive that may come out of the event are all forms of positive reappraisal that are likely to be related to increased positive affect in the face of stress. The facilitator and participant then practice reappraising recent small events in the participant's life. We explicitly do not focus on trying to reappraise the experience of testing positive for HIV. Instead we start with small, relatively minor events (eg, being late to work; encountering a rude person on the street; traffic) to develop the skill of positive reappraisal. Although it is not a proximal goal of the present intervention given its brief duration, with continued practice an individual can learn to positively reappraise virtually any event. ${ }^{109}$ Home practice consists of reporting a relatively minor stressor each day, then listing ways in which the event can be positively reappraised. The daily formal mindfulness practice (10 minutes of mindful breathing), the daily gratitude journal, and the brief emotion reports continue.

\section{Session 4}

In Session 4, we focus on the participant's personal strengths and the process of setting (and attaining) achievable goals. The facilitator asks the participant to list his or her personal strengths or positive qualities. After the participant lists them, the facilitator then lists strengths that he has seen in the participant over the 4 weeks of the intervention. In our pilot work, this was a powerful positive experience for participants. It was particularly effective given that participants were in the midst of the stressful early months after HIV diagnosis. The next portion of the session concerns defining and setting attainable goals. We define attainable goals as having four characteristics: 1) they are realistic and can be reasonably completed in the allotted time; 2) they are clear; 3 ) they are challenging but not impossible or too global; and 4) they have a clear end point so it is obvious when the goal has been successfully completed. The facilitator then works with the participant to set some attainable goals for the coming week. 
The home practice for Session 4 consists of listing a strength each day and how it was "expressed" behaviorally that day, working toward one of the goals each day, and noting progress each day. The 10-minute mindful breathing, the gratitude journal, and the daily affect reports continue this week.

\section{Session 5}

The focus in Session 5 is on altruistic behaviors or small acts of kindness. The previous 4 sessions encourage participants to focus on themselves. The purpose of Session 5 is to intentionally focus on other people. The facilitator emphasizes that even though the participant may be going through a very difficult time in his or her life, he/she can still help other people through small acts of kindness (including expressing gratitude to people who performed acts of kindness or helped care for them). In addition to the mindful breathing, daily gratitude journal, and daily affect reports, the home practice for Session 5 consists of doing one small act of kindness each day and noting it.

\section{Session 6}

Session 6 is conducted by phone and focuses on reviewing the previous week's home practice, evaluation of each of the eight skills, evaluation of the intervention overall, and planning for continued practice of the skills.

\section{Content of the control sessions}

Participants in the control condition also have five one-onone sessions with a facilitator. The sessions are comparable in length to the intervention sessions (approximately one hour) but consist of an interview and do not have didactic portions or skills practice. These sessions were designed to remove the positive affect component of the intervention, while maintaining any nonspecific effects arising from one-on-one contact with a sympathetic facilitator and an opportunity to share one's personal stories and concerns. The interviews include 1) life history (qualitative); 2) health history (qualitative), including use of complementary and alternative medicine and physical activity; 3) personality and diet questionnaires; 4) social support and social network; 5) meaning and purpose; 6) (via telephone) the ranking of sessions as to whether participants would recommend the sessions to a friend; and 7) (via telephone) the participant's rating of enjoyment of sessions.

Home practice for the control group consists of brief daily affect reports over the 5 weeks of the control sessions. At the start of sessions two through five, the facilitator reviews the previous week's affect diary with the participant.
After the Time 4 assessment (15 months post-diagnosis), participants in the control condition are given the opportunity to access an online, self-paced version of the intervention.

\section{Payment of participants}

Participants are paid $\$ 20$ for each intervention/control session, \$25 for the first two assessments, and \$50 for each of the assessments at Time 3 and Time 4, for a total of $\$ 250$ for completing the entire study. In addition, we reimburse for transportation (eg, cab fare, bus fare, or parking) and provide a snack for each assessment and intervention/control session.

\section{Training and intervention fidelity}

There were two groups of staff, each of whom required different training: assessment interviewers (assessors) and session facilitators. All staff members received a minimum of 30 hours of training which took place over several weeks and included: 1) privacy and confidentiality training in Health Insurance Portability and Accountability Act (HIPAA) security practices and human subjects protection; 2) technology training, including use of laptops, computer-assisted personal interview programs, digital audio software, and data tracking procedures on the study website; 3 ) training in interviewing techniques, which addressed building rapport, working with diverse populations, cultural sensitivity, population-specific issues and referrals, and basic quantitative and qualitative interview skills; 4) suicidality assessment protocol; 5) interview/session roleplays; and 6) site visits to locations where assessments and control/intervention sessions took place. Ongoing training provided updates on HIV treatment and weekly group supervision, and as-needed individual supervision to address individual cases and procedural issues for assessors and facilitators. Assessors received additional training in obtaining informed consent and the video recording protocol. Facilitators attended a separate training that included detailed overviews of the intervention approach and procedures. Specific techniques for adhering to a manualized intervention while allowing for flexibility to address individual participant needs were taught, role-played, and supplemented by instructional readings. Assessors and facilitators were bilingual and bicultural. The majority of staff conducting Spanish-language interventions and assessments were native Spanish speakers.

Following the training, staff conducted mock sessions. The audio recordings of these sessions were reviewed by the principal investigator and project director, who then met oneon-one with interviewers/facilitators to provide feedback on 
interviewing and intervention techniques. Mock interviews were repeated until assessors/facilitators were proficient with using software, familiar with delivery of quantitative questionnaires, skilled at conducting the qualitative portion of the interview and, for the intervention facilitators, were comfortable and familiar with each of the five intervention sessions.

\section{Intervention fidelity training and monitoring}

Monitoring of fidelity of intervention and control sessions during the course of the study included: 1) development of detailed curriculum manuals for each of the sessions; 2) intensive training; 3 ) incorporation of mock training sessions that enabled us to ensure all facilitators met performance criteria for intervention/control session delivery; and 4) audio recording of sessions. Audio recordings of facilitator sessions were reviewed by the project director to assess adherence to the protocol, delivery, interpersonal skills, facilitator/participant rapport, and session flow.

\section{Measures}

Detailed descriptions of the measures are provided in Table 1.

\section{Planned analyses}

The primary outcome measure is positive affect. Our first aim is to determine the efficacy of the intervention for increasing positive affect at Times 2, 3, and 4. The second aim tests positive affect as a mediator of intervention effects on psychological well-being (eg, depression), health behaviors (eg, HIV transmission risk, engagement in care, medication adherence) and physical health (eg, CD4, viral load, symptoms). The third aim tests moderation of intervention effects by baseline characteristics such as gender, race/ethnicity, and personality (see Figure 1).

We will first examine baseline characteristics of the sample, stratified by experimental group, to ensure that key variables (positive affect, mental and physical health, and demographics) are indeed evenly distributed in the randomization. Before testing hypotheses, we will also examine the proportion of missing data at each time point in order to address any concern regarding possible bias due to differential attrition. Completers and dropouts will be compared on baseline variables using independent $t$ and Fisher's exact tests. Variables showing substantial group differences at baseline will be candidates for inclusion as covariates in tests of hypotheses.
Given that this study is a treatment evaluation, we will conduct intention-to-treat analyses. We will supplement these analyses with dose-response analyses, using ordinary or logistic regression, depending on whether outcomes are continuous or dichotomous, to test whether various measures of participation (eg, number of sessions attended, days of homework completed) affect outcomes.

Aim 1. Determine the efficacy of the Intervention for those Recently Informed of their Seropositive Status (IRISS) to increase frequency and intensity of our primary outcome, positive affect, during the intervention and at 5, 10, and 15 months after diagnosis. Tests of intervention effects will be conducted with multiple-group growth models, with coefficients chosen to reflect the hypothesized pattern of change. We expect frequency and intensity of positive affect, as measured, respectively, by the modified Differential Emotions Scale (mDES) and Positive and Negative Affect Schedule (PANAS) (see Table 1), to increase for the intervention group over the course of the intervention, and to be maintained thereafter. The most specific manifest-variable test of the hypothesis as a whole is the difference between groups on the contrast between baseline and the following three time points. On a more piecemeal basis, differences in means or in change scores can be tested with independent $t$-tests comparing the intervention to the control group.

Aim 2. Test the effects of IRISS on psychological and physical health and health behaviors, and determine whether increases in positive affect are responsible for improvements in these outcomes. The tests of effects here are the same as those in Aim 1, with different outcome variables. Some, like clinical depression, are binary, but these can be handled by Mplus (Muthén and Muthén, Los Angeles, CA, USA) through probit regression. Others, like viral load, are known to have strong positive skew and will be (log) transformed before analysis. Determining whether increases in positive affect are responsible for these changes requires mediation analysis. Since we expect both the outcomes and these potential "mediators" to be products of the intervention, with perhaps no clear separation in time, the first step in these analyses will be to examine whether changes in positive affect precede or coincide with changes in the outcomes. MacKinnon et $\mathrm{al}^{110}$ conducted a Monte Carlo study of 14 procedures for testing mediation effects, found the classic method of Baron and Kenny ${ }^{111}$ unacceptably weak, and recommended testing the product of the coefficients in the mediation path by reference to the distribution of the product of two normal variates (which is not itself normal). As recommended by Shrout and Bolger $^{112}$ we will use Mplus to bootstrap the product term. 
Given the dependency of indirect effects on the time interval, for multiwave models we will compute overall, rather than time-specific, indirect effects. ${ }^{113}$

Aim 3. Evaluate the extent to which personality, sex, or race/ethnicity moderate the effects of IRISS on these outcomes. Since we will be exploring moderation and mediation separately, moderation can be tested simply by the addition of interaction terms, with components appropriately centered.

\section{Discussion}

The first few months after HIV diagnosis provide a window of opportunity for intervention in which participants are establishing new patterns of sexual risk and health behaviors. Although the period immediately following diagnosis is associated with significantly elevated levels of depression and anxiety, there are few interventions designed expressly for people newly diagnosed with HIV.

Based on increasing evidence from our research team and others that positive affect has adaptive functions in the context of health-related stress, we developed and are testing a theory-based positive affect skills intervention for people newly diagnosed with HIV. By emphasizing the importance of positive affect in the stress process we may appear to minimize the pain and serious individual and societal consequences associated with major stressful events. We are not advocating a simplistic “don't worry, be happy" approach, nor do we believe that simply increasing positive affect will prove to be a cure-all for the very real and complex issues facing people newly diagnosed with HIV. Such a stance could easily degenerate into blaming the victim for not thinking the positive thoughts that may prevent depression or other negative consequence of enduring stress.

However, an intervention to increase positive affect in the months after testing positive for HIV may set the stage for a cascade of adaptive consequences. In addition, the focus on positive affect will likely make the proposed intervention more attractive to providers and participants alike, and serve as an antidote to the increasingly pervasive "prevention fatigue". ${ }^{114-116}$

Further, in pilot testing this intervention we learned that participants were not the only ones whose positive affect increased; facilitators, staff, and investigators also experienced increases in positive affect. Ultimately, given the high levels of stress, distress, and depression documented in this population of people newly diagnosed with HIV, we consider increasing positive affect to be an inherently worthwhile intervention goal.

\section{Acknowledgements}

This work was funded by R01MH084723 and K24MH093225 from the National Institute of Mental Health, and by K01AT005270 from the National Center for Complementary and Alternative Medicine. It is registered at clinicaltrials.gov as registration number NCT00720733.

\section{Disclosure}

The authors report no conflicts of interest in this work.

\section{References}

1. Bing EG, Burnam MA, Longshore D, et al. Psychiatric disorders and drug use among human immunodeficiency virus-infected adults in the United States. Arch Gen Psychiatry. 2001;58(8):721-728.

2. Walker RD, Howard MO, Lambert MD, Suchinsky R. Psychiatric and medical comorbidities of veterans with substance use disorders. Hosp Community Psychiatry. 1994;45(3):232-237.

3. Marks G, Bingman CR, Duval TS. Negative affect and unsafe sex in HIV-positive men. AIDS and Behavior. 1998;2(2):89-99.

4. Latkin C, Mandell W. Depression as an antecedent of frequency of intravenous drug use in an urban, nontreatment sample. Int $J$ Addict. 1993;28:1601-1612.

5. Gordillo V, del Amo J, Soriano V, González-Lahoz J. Sociodemographic and psychological variables influencing adherence to antiretroviral therapy. AIDS. 1999;13(13):1763-1769.

6. Holzemer WL, Corless IB, Nokes KM, et al. Predictors of self-reported adherence in persons living with HIV disease. AIDS Patient Care STDS. 1999;13(3):185-197.

7. Paterson DL, Swindells S, Mohr J, et al. Adherence to protease inhibitor therapy and outcomes in patients with HIV infection. Ann Intern Med. 2000;133(1):21-30.

8. Ickovics JR, Hamburger ME, Vlahov D, et al. Mortality, CD4 cell count decline, and depressive symptoms among HIV-seropositive women: longitudinal analysis from the HIV Epidemiology Research Study. Jama. 2001;285(11):1466-1474.

9. Leserman J. The effects of depression, stressful life events, social support, and coping on the progression of HIV infection. Curr Psychiatry Rep. 2000;2(6):495-502.

10. Mayne TJ, Vittinghoff E, Chesney MA, Barrett DC, Coates TJ. Depressive affect and survival among gay and bisexual men infected with HIV. Arch Intern Med. 1996;156(19):2233-2238.

11. Lyubomirsky S, King L, Diener E. The benefits of frequent positive affect: does happiness lead to success? Psychol Bull. 2005;131(6): 803-855.

12. Pressman SD, Cohen S. Does positive affect influence health? Psychol Bull. 2005;131(6):925-971.

13. Folkman S. Positive psychological states and coping with severe stress. Soc Sci Med. 1997;45:1207-1221.

14. Folkman S, Moskowitz JT. Positive affect and the other side of coping. Am Psychol. 2000;55(6):647-654.

15. Fredrickson BL, Joiner T. Positive emotions trigger upward spirals toward emotional well-being. Psychol Sci. 2002;13(2):172-175.

16. Zautra A, Smith B, Affleck G, Tennen H. Examinations of chronic pain and affect relationships: applications of a dynamic model of affect. J Consult Clinical Psychol. 2001;69(5):786-795.

17. Carrico AW, Moskowitz JT. Positive affect promotes engagement in care after HIV diagnosis. Health Psychol. 2014;33(7):686-689.

18. Folkman S, Chesney MA, Christopher-Richards A. Stress and coping in caregiving partners of men with AIDS. Psychiatr Clin North Am. 1994; 17(1):35-53.

19. Folkman S, Chesney MA, Pollack L, Coates T. Stress, control, coping, and depressive mood in human immunodeficiency virus-positive and -negative gay men in San Francisco. J Nerv Ment Dis. 1993;181(7):409-416. 
20. Moskowitz JT. Positive affect predicts lower risk of aids mortality. Psychosom Med. 2003;65(4):620-626.

21. Moskowitz JT, Epel ES, Acree M. Positive affect uniquely predicts lower risk of mortality in people with diabetes. Health Psychol. 2008;27(1) (Suppl):S73-S82.

22. Cohen J. Breakthrough of the year. HIV treatment as prevention. Science. 2011;334(6063):1628.

23. Craw JA, Gardner LI, Marks G, et al. Brief strengths-based case management promotes entry into HIV medical care: results of the antiretroviral treatment access study-II. J Acquir Immune Defic Syndr. 2008;47(5):597-606.

24. Chesney M, Chambers D, Taylor JM, Johnson LM, Folkman S. Coping effectiveness training for men living with HIV: results from a randomized clinical trial testing a group-based intervention. Pyschosom Med. 2003;65(6):1038-1046.

25. Johnson BT, Carey MP, Chaudoir SR, Reid AE. Sexual risk reduction for persons living with HIV: research synthesis of randomized controlled trials, 1993 to 2004. J Acquir Immune Defic Syndr. 2006;41(5): $642-650$

26. Crepaz N, Lyles CM, Wolitski RJ, et al. Do prevention interventions reduce HIV risk behaviours among people living with HIV? A metaanalytic review of controlled trials. Aids. 2006;20(2):143-157.

27. Berg CJ, Michelson SE, Safren SA. Behavioral aspects of HIV care adherence, depression, substance use, and HIV-transmission behaviors Infect Dis Clin North Am. 2007;21(1):181-200, x.

28. Himelhoch S, Medoff DR, Oyeniyi G. Efficacy of group psychotherapy to reduce depressive symptoms among HIV-infected individuals: a systematic review and meta-analysis. AIDS Patient Care STDS 2007;21(10):732-739.

29. Zuccotti G, Smith JM. New weapons needed to fight HIV. JAMA. 2007;298(21):2545.

30. Rabkin JG. HIV and depression: 2008 review and update. Curr HIV/ AIDS Rep. 2008;5(4):163-171.

31. Centers for Disease Control and Prevention. Estimated HIV incidence in the United States, 2007-2010. HIV Surveillance Supplemental Report 2012;17(4). Available from: http:/www.cdc.gov/hiv/topics/ surveillance/resources/reports/. Accessed January 1, 2014.

32. Holtgrave DR, McGuire JF, Milan J Jr. The magnitude of key HIV prevention challenges in the United States: implications for a new national HIV prevention plan. Am J Public Health. 2007;97(7):1163-1167.

33. Hult JR, Maurer SA, Moskowitz JT. "I'm sorry, you're positive": a qualitative study of individual experiences of testing positive for HIV. AIDS Care. 2009;21(2):185-188.

34. Moskowitz JT, Wrubel J, Hult J, Maurer MJ, Stephens E. Illness Appraisals and Coping in People Newly Diagnosed with HIV. Washington, DC: American Psychological Association; 2007.

35. Ironson G, LaPerriere AR, Antoni MH, O'Hearn P. Changes in immune and psychological measures as a function of anticipation and reaction to news of HIV-1 antibody status. Psychosom Med. 1990;52(3): 247-270.

36. Jacobsen PB, Perry SW, Hirsch D-A. Behavioral and psychological responses to HIV antibody testing. J Consult Clin Psychol. 1990;58(1): 31-37.

37. LaPerriere AR, Antoni MH, Schneiderman N, et al. Exercise intervention attenuates emotional distress and natural killer cell decrements following notification of positive serologic status for HIV-1. Biofeedback Self Regul. 1990;15(3):229-242.

38. Ostrow DG, Joseph JG, Kessler R, Soucy J. Disclosure of HIV antibody status: Behavioral and mental health correlates. AIDS Educ Prev. 1989;1(1):1-11.

39. Perry SW, Fishman B, Jacobsberg L, Frances AJ. Relationships over 1 year between lymphocyte subsets and psychosocial variables among adults with infection by human immunodeficiency virus. Arch Gen Psychiatry. 1992;49(5):396-401.

40. Rundell JR, Paolucci SL, Beatty DC, Boswell RN. Psychiatric illness at all stages of Human Immunodeficiency Virus infection. Am J Psychiatry. 1988;145(5):652-653.
41. Bhatia R, Hartman C, Kallen MA, Graham J, Giordano TP. Persons newly diagnosed with HIV infection are at high risk for depression and poor linkage to care: results from the Steps Study. AIDS Behav. 2011;15(6):1161-1170.

42. Antoni MH, Ironson G, Schneiderman N. Cognitive-Behavioral Stress Management for Individuals Living with HIV. New York: Oxford University Press; 2007.

43. Folkman S, Chesney MA, Collette L, Boccellari A, Cooke M. Postbereavement depressive mood and its prebereavement predictors in HIV+ and HIV- gay men. J Pers Social Psychol. 1996;70(2):336-348.

44. Moskowitz JT, Folkman S, Acree M. Do positive psychological states shed light on recovery from bereavement? Findings from a 3-year longitudinal study. Death Stud. 2003;27(6):471-500.

45. Fredrickson BL, Tugade MM, Waugh CE, Larkin GR. What good are positive emotions in crises? A prospective study of resilience and emotions following the terrorist attacks on the United States on September 11th, 2001. J Pers Soc Psychol. 2003;84(2):365-376.

46. Tice DM, Baumeister RF, Shmueli D, Muraven M. Restoring the self: Positive affect helps improve self-regulation following ego depletion. J Exp Soc Psychol. 2007;43(3):379-384.

47. Wichers MC, Myin-Germeys I, Jacobs N, et al. Evidence that momentto-moment variation in positive emotions buffer genetic risk for depression: a momentary assessment twin study. Acta Psychiatr Scand. 2007;115(6):451-457.

48. Zautra AJ, Johnson LM, Davis MC. Positive affect as a source of resilience for women in chronic pain. $J$ Consult Clin Psychol. 2005;73(2):212-220.

49. Ong AD, Bergeman CS, Bisconti TL, Wallace KA. Psychological resilience, positive emotions, and successful adaptation to stress in later life. J Pers Soc Psychol. 2006;91(4):730-749.

50. Fredrickson BL, Levenson RW. Positive emotions speed recovery from the cardiovascular sequelae of negative emotions. Cogn Emot. 1998; 12:191-220.

51. Chida Y, Steptoe A. Positive psychological well-being and mortality: A quantitative review of prospective observational studies. Psychosom Med. 2008;70(7):741-756.

52. Mroczek DK, Stawski RS, Turiano NA, et al. Emotional reactivity and mortality: longitudinal findings from the VA normative aging study. J Gerontol B Psychol Sci Soc Sci. Epub October 29, 2013.

53. Fredrickson BL. What good are positive emotions? Rev Gen Psychol. 1998;2(3):300-319.

54. Antoni MH, Goldstein D, Ironson G, LaPerriere A, Fletcher MA, Schneiderman N. Coping responses to HIV-1 serostatus notification predict concurrent and prospective immunologic status. Clinical Psychology and Psychotherapy. 1995;2:(4):234-248.

55. Patterson TL, Shaw WS, Semple SJ, et al. Relationship of psychosocial factors to HIV disease progression. Ann Behav Med. 1996;18(1): 30-39.

56. Steptoe A, Dockray S, Wardle J. Positive Affect and Psychobiological Processes Relevant to Health. J Pers. 2009;77(6):1747-1776.

57. Keltner D, Bonanno GA. A study of laughter and dissociation: Distinct correlates of laughter and smiling during bereavement. $J$ Pers Soc Psychol. 1997;73(4):687-702.

58. Futterman AD, Kemeny ME, Shapiro D, Fahey JL. Immunological and physiological changes associated with induced positive and negative mood. Psychosom Med. 1994;56(6):499-511.

59. Stone AA, Cox DS, Valdimarsdottir H, Jandorf L, Neale JM. Evidence that secretory IgA antibody is associated with daily mood. $J$ Pers Soc Psychol. 1987;52(5):988-993.

60. Ickovics JR, Milan S, Boland R, Schoenbaum E, Schuman P, Vlahov D. Psychological resources protect health: 5-year survival and immune function among HIV-infected women from four US cities. Aids. 2006;20(14):1851-1860.

61. Antoni MH. Effects of cognitive behavioral stress management intervention on depressed mood, distress levels, and immune status in HIV infection. In: Johnson SL, Hayes AM, Field TM, Schneiderman N, McCabe PM, editors. Stress, Coping, and Depression. Mahwah (NJ) Erlbaum; 2000:241-263. 
62. Antoni MH, Baggett L, Ironson G, et al. Cognitive-behavioral stress management intervention buffers distress responses and immunologic changes following notification of HIV-1 seropositivity. J Consult Clin Psychol. 1991;59(6):906-915.

63. Antoni MH, Cruess S, Cruess DG, et al. Cognitive-behavioral stress management reduces distress and 24-hour urinary free cortisol output among symptomatic HIV-infected gay men. Ann Beh Med. 2000;22(1): 29-37.

64. Antoni MH, Carrico AW, Durán RE, et al. Randomized clinical trial of cognitive behavioral stress management on human immunodeficiency virus viral load in gay men treated with highly active antiretroviral therapy. Psychosom Med. 2006;68(1):143-151.

65. Mustanski B. The influence of state and trait affect on HIV risk behaviors: a daily diary study of MSM. Health Psychol. 2007;26(5): 618-626.

66. Carrico AW, Woods WJ, Siever MD, et al. Positive affect and processes of recovery among treatment-seeking methamphetamine users. Drug Alcohol Depend. 2013;132(3):624-629.

67. Reed MB, Aspinwall LG. Self-affirmation reduces biased processing of health-risk information. Motivation and Emotion. 1998;22(2): 99-132.

68. Salovey P, Birnbaum D. Influence of mood on health-relevant cognitions. J Pers Soc Psychol. 1989;57(3):539-551.

69. Folkman S. The case for positive emotions in the stress process. Anxiety Stress Coping. 2008;21(1):3-14.

70. Lazarus RS, Folkman S. Stress, Appraisal, and Coping. New York: Springer;1984.

71. Fredrickson BL, Branigan C. Positive emotions broaden the scope of attention and thought-action repertoires. Cogn Emot. 2005;19(3): 313-332.

72. Rowe G, Hirsh JB, Anderson AK. Positive affect increases the breadth of attentional selection. Proc Natl Acad Sci U S A. 2007;104(1): 383-388.

73. Wadlinger HA, Isaacowitz DM. Positive mood broadens visual attention to positive stimuli. Motiv Emot. 2006;30(1):89-101.

74. Cunningham MR. What do you do when you're happy or blue? Mood, expectancies, and behavioral interest. Motiv Emot. 1988;12(4): 309-331.

75. Gable SL, Gonzaga GC, Strachman A. Will you be there for me when things go right? Supportive responses to positive event disclosures. J Pers Soc Psychol. 2006;91(5):904-917.

76. Gable SL, Reis HT, Impett EA, Asher ER. What do you do when things go right? The intrapersonal and interpersonal benefits of sharing positive events. J Pers Soc Psychol. 2004;87(2):228-245.

77. Waugh CE, Fredrickson BL. Nice to know you: Positive emotions, self-other overlap, and complex understanding in the formation of a new relationship. J Posit Psychol. 2006;1(2):93-106.

78. Moskowitz JT, Hult JR, Duncan LG, et al. A Positive affect intervention for people experiencing health-related stress: development and non-randomized pilot test. J Health Psychol. 2012;17(5):677-692.

79. Lewinsohn PM, Amenson CS. Some relations between pleasant and unpleasant mood-related events and depression. J Abnorm Psychol. 1978;87(6):644-654.

80. Lewinsohn PM, Clarke GN, Hoberman HM. The coping with depression course: review and future directions. Canadian Journal of Behavioural Science. 1989;21(4):470-493.

81. Lewinsohn PM, Sullivan M, Grosscup SJ. Changing reinforcing events: An approach to the treatment of depression. Psychotherapy: Theory, Research, and Practice. 1980;17(3):322-334.

82. Krause N. Positive life events and depressive symptoms in older adults. Behav Med. 1998;14(3):101-112.

83. Langston CA. Capitalizing on and coping with daily-life events: Expressive responses to positive events. Journal of Personality and Social Psychology. 1994;67(6):1112-1125.

84. Bryant FB. A four-factor model of perceived control: Avoiding, coping, obtaining, and savoring. Journal of Personality. 1989;57(4): $773-797$.
85. Emmons RA. Thanks! How the New Science of Gratitude Can Make You Happier. New York: Houghton Mifflin; 2007.

86. Kashdan TB, Uswatte G, Julian T. Gratitude and hedonic and eudaimonic well-being in Vietnam war veterans. Behav Res Ther. 2006;44(2):177-199.

87. Lyubomirsky S, Sheldon KM, Schkade D. Pursuing happiness: The architecture of sustainable change. Review of General Psychology. 2005;9(2):111-131.

88. Kabat-Zinn J. Mindfulness-based interventions in context: Past, present, and future. Clinical Psychology: Science and Practice. 2003;10(2):144-156.

89. Grossman P, Tiefenthaler-Gilmer U, Raysz A, Kesper U. Mindfulness training as an intervention for fibromyalgia: evidence of postintervention and 3-year follow-up benefits in well-being. Psychother Psychosom. 2007;76(4):226-233.

90. Shapiro M, Brown KW, Biegel GM. Teaching self-care to caregivers: Effects of mindfulness-based stress reduction on the mental health of therapists in training. Training and Education in Professional Psychology. 2007;1(2):105-115.

91. Cresswell JD, Myers HF, Cole SW, Irwin MR. Mindfulness meditation training effects on CD4+ T lymphocytes in HIV-1 infected adults: A small randomized controlled trial. Brain Behav Immun. 2009;23(2):184-188.

92. Sears SR, Stanton AL, Danoff-Burg S. The yellow brick road and the emerald city: Benefit finding, positive reappraisal coping and posttraumatic growth in women with early-stage breast cancer. Health Psychol. 2003;22(5):487-497.

93. Carver CS, Scheier MF. Situational coping and coping dispositions in a stressful transaction. J Pers Soc Psychol. 1994;66(1):184-195.

94. Moskowitz JT, Folkman S, Collette L, Vittinghoff E. Coping and mood during AIDS-related caregiving and bereavement. Ann Behav Med. 1996;18(1):49-57.

95. Moskowitz JT, Hult JR, Bussolari C, Acree M. What works in coping with HIV? A meta-analysis with implications for coping with serious illness. Psychol Bull. 2009;135(1):121-141.

96. Chesney MA, Folkman S, Chambers D. Coping effectiveness training for men living with HIV: Preliminary findings. International Journal of STD and AIDS. 1996;7(Suppl 2):75-82.

97. Koole SL, Smeets K, van Knippenberg Ad, Dijksterhuis Ap. The cessation of rumination through self-affirmation. Journal of Personality and Social Psychology. 1999;77(1):111-125.

98. Taylor SE, Kemeny ME, Aspinwall LG, Schneider SG, Rodriguez R, Herbert M. Optimism, coping, psychological distress, and high-risk sexual behavior among men at risk for acquired immunodeficiency syndrome (AIDS). J Pers Social Psychol. 1992;63(3):460-473.

99. Taylor SE, Lobel M. Social comparison activity under threat: Downward evaluation and upward contacts. Psychol Rev. 1989;96(4):569-575.

100. Sikkema KJ, Kalichman SC, Kelly, JA, Koob JJ. Group intervention to improve coping with AIDS-related bereavement: Model development and an illustrative clinical example. AIDS Care. 1995;7(4): 463-475.

101. Lent RW, Singley D, Sheu H-B, et al. Social cognitive predictors of domain and life satisfaction: Exploring the theoretical precursors of subjective well-being. Journal of Counseling Psychology. 2005;52(3):429-442.

102. Brunstein JC, Schultheiss OC, Grassmann R. Personal goals and emotional well-being: the moderating role of motive dispositions. J Pers Soc Psychol. 1998;75(2):494-508.

103. Carver CS, Scheier MF. Origins and functions of positive and negative affect: a control process view. Psychological Review. 1990;97(1):19-35.

104. Musick MA, Wilson J. Volunteering and depression: the role of psychological and social resources in different age groups. Soc Sci Med. 2003;56(2):259-269.

105. Oman D, Thoresen CE, McMahon K. Volunteerism and mortality among the community-dwelling elderly. J Health Psychol. 1999;4(3):301-316. 
106. Moen P, Dempster-McCain D, Williams RM. Successful aging: a lifecourse perspective on women's multiple roles and health. American Journal of Sociology. 1993;97(6):1612-1632.

107. Brown SL, Nesse RM, Vinokur AD, Smith DM. Providing social support may be more beneficial than receiving it: results from a prospective study of mortality. Psychol Sci. 2003;14(4):320-327.

108. Penner LA, Dovidio JF, Piliavin JA, Schroeder DA. Prosocial behavior: multilevel perspectives. Annu Rev Psychol. 2005;56:365-392.

109. Tedeschi RG, Park CL, Calhoun LG, editors. Posttraumatic Growth: Positive Changes in the Aftermath of Crisis. Mahwah (NJ): Erlbaum; 1998.

110. MacKinnon DP, Lockwood CM, Hoffman JM, West SG, Sheets V. A comparison of methods to test mediation and other intervening variable effects. Psychol Methods. 2002;7(1):83-104.

111. Baron RM, Kenny DA. The moderator-mediator variable distinction in social psychological research: conceptual, strategic, and statistical considerations. J Pers Soc Psychol. 1986;51(6):1173-1182.

112. Shrout PE, Bolger N. Mediation in experimental and nonexperimental studies: new procedures and recommendations. Psychol Methods. 2002;7(4):422-445.

113. Gollob HF, Reichardt CS. Interpreting and estimating indirect effects assuming time lags really matter. In: Collins LM, Horn JL, editors. Best Methods for the Analysis of Change: Recent Advances, Unanswered Questions, Future Directions. Washington, DC: American Psychological Association; 1991:243-259.

114. Chen SY, Weide D, McFarland W. Are the recent increases in sexual risk behavior among older or younger men who have sex with men? Answer: both. Aids. 2003;17(6):942-943.

115. Ostrow DE, Fox KJ, Chmiel JS, et al. Attitudes towards highly active antiretroviral therapy are associated with sexual risk taking among HIV-infected and uninfected homosexual men. Aids. 2002;16(5):775-780.

116. Stockman JK, Schwarcz SK, Butler LM, et al. HIV prevention fatigue among high-risk populations in San Francisco. J Acquir Immune Defic Syndr. 2004;35(4):432-434.

117. Watson D, Clark LA, Tellegen A. Development and validation of brief measures of positive and negative affect: The PANAS scales. Journal of Personality and Social Psychology. 1988;54(6): 1063-1070.

118. Spitzer RL, Kroenke K, Williams JB. Validation and utility of a selfreport version of PRIME-MD: the PHQ primary care study. JAMA. 1999;282(18):1737-1744.

119. Radloff LS. The CES-D scale a self-report depression scale for research in the general population. Applied Psychological Measurement 1977;1(3):385-401

120. Spielberger CD, Gorsuch RL, Lushene RE. STAI Manual for the StateTrait Anxiety Inventory. Palo Alto (CA): Consulting Psychologists Press; 1970.

121. Cohen S. Perceived stress in a probability sample of the United States In: Spacapan S, Oskamp S, editors. The Social Psychology of Health. The Claremont Symposium on Applied Social Psychology. Thousand Oaks (CA): Sage Publications, Inc.; 1988:31-67.

122. Justice AC, Holmes W, Gifford AL, et al. Development and validation of a self-completed HIV symptom index. J Clin Epidemiol. 2001;54(Suppl 1):S77-S90.

123. Vallabhaneni S, McConnell JJ, Loeb L, et al. Changes in seroadaptive practices from before to after diagnosis of recent HIV infection among men who have sex with men. PLoS One. 2013;8(2):e55397.

124. Simoni JM, Kurth AE, Pearson CR, Pantalone DW, Merrill JO, Frick PA. Self-report measures of antiretroviral therapy adherence: A review with recommendations for HIV research and clinic management. AIDS Behav. 2006;10(3):227-245.

125. Walsh JC, Mandalia S, Gazzard BG. Responses to a 1 month selfreport on adherence to antiretroviral therapy are consistent with electronic data and virological treatment outcome. Aids. 2002;16(2): 269-277.
126. Vickers RR Jr, Conway TL, Hervig LK. Demonstration of replicable dimensions of health behaviors. Prev Med. 1990;19(4):377-401.

127. Billings DW, Revelle W. Savor the flavor and cope with the mope: explicating the asymmetric associations between personality and daily mood. Paper presented at: International Society for Research on Emotion August, 2000; Quebec City, Quebec.

128. Folkman S, Lazarus RS, Pimley S, Novacek J. Age differences in stress and coping processes. Psychol Aging. 1987;2(2):171-184.

129. Moos RH. Coping Responses Inventory. Lutz (FL): Psychological Assessment Resources, Inc.; 1993.

130. Tennen H, Affleck G, Urrows S, Higgins P, Mendola R. Perceiving control, construing benefits, and daily processes in rheumatoid arthritis. Canadian Journal of Behavioural Science. 1992;242(2): 186-203.

131. Zuckerman M, Gagne M. The COPE revised: proposing a 5-factor model of coping strategies. Journal of Research in Personality. 2003;37(3):169-204.

132. Bauman LJ, Camacho S, Weiss ES. Social support systems of mothers with HIV/AIDS. Paper presented at: NIMH Conference on Role of Families in Preventing and Adapting to HIV/AIDS. 1997; Baltimore, MD.

133. Costa PT, McCrae RR. NEO PI-R Professional Manual: Revised NEO Personality Inventory and NEO Five-Factor Inventory. Lutz (FL): Psychological Assessment Resources, Inc.; 1991.

134. Scheier MF, Carver CS, Bridges MW. Distinguishing optimism from neuroticism (and trait anxiety, self-mastery, and self-esteem): a reevaluation of the Life Orientation Test. J Pers Soc Psychol. 1994;67(6):1063-1078.

135. Rosenberg M. Society and the Adolescent Self-Image. Princeton (NJ): Princeton University Press; 1965.

136. Janoff-Bulman R. Assumptive worlds and the stress of traumatic events: applications of the schema construct. Social Cognition. 1989;7(2):113-136.

137. Adler NE, Epel ES, Castellazzo G, Ickovics JR. Relationship of subjective and objective social status with psychological and physiological functioning: preliminary data in healthy white women. Health Psycholog. 2000;19(6):586-592.

138. Gruen RJ, Folkman S, Lazarus RS. Centrality and individual differences in the meaning of daily hassles. J Pers. 1988;56(4):743-762.

139. Sarason IG, Johnson JH, Siegel JM. Assessing the impact of life changes: development of the Life Experiences Survey. J Consult Clin Psychol. 1978;46(5):932-946.

140. McCullough ME, Emmons RA, Tsang J. The grateful disposition: a conceptual and empirical topography. J Pers Social Psychol. 2002;82(1):112-127.

141. Baer RA, Smith GT, Hopkins J, Krietemeyer J, Toney L. Using self-report assessment methods to explore facets of mindfulness. Assessment. 2006;13(1):27-45.

142. Chesney MA, Neilands TB, Chambers DB, Taylor JM, Folkman S. A validity and reliability study of the coping self-efficacy scale. $\mathrm{Br} J$ Health Psychol. 2006;11(Pt 3):421-437.

143. Rusting CL, Larsen RJ. Extraversion, neuroticism, and susceptibility to positive and negative affect: A test of two theoretical models. Pers Indiv Differences. 1997;22(5):607-612.

144. Costa PT, Somerfield MR, McCrae RR. Personality and Coping: A Reconceptualization. In: Zeidner M, Endler NS, editors. Handbook of Coping: Theory, Research, Applications. New York: John Wiley and Sons; 1995.

145. Falck RS, Wang J, Carlson RG, Siegal HA. The epidemiology of physical attack and rape among crack-using women. Violence Vict. 2001;16(1):79-89.

146. Baños RM, Guillén V. Psychometric characteristics in normal and social phobic samples for a Spanish version of the Rosenberg SelfEsteem Scale. Psychol Rep. 2000;87(1):269-274. 


\section{Publish your work in this journal}

The Open Access Journal of Clinical Trials is an international, peerreviewed, open access journal publishing original research, reports, editorials, reviews and commentaries on all aspects of clinical trial design, management, legal, ethical and regulatory issues, case record form design, data collection, quality assurance and data auditing

Submit your manuscript here: http://www.dovepress.com/open-access-journal-of-clinical-trials-journal methodologies. The manuscript management system is completely online and includes a very quick and fair peer-review system, which is all easy to use. Visit http://www.dovepress.com/testimonials.php to read real quotes from published authors. 